Research Article

\title{
INVESTIGATION OF EFFECTS OF DIFFERENT CUTTING AND MACHINING PARAMETERS ON SURFACE ROUGHNESS AND MAIN CUTTING FORCES VIA RESPONSE SURFACE METHOD
}

\section{Hüseyin GÜRB $\ddot{U} Z^{1 *}$, Yunus Emre GÖNÜLAÇAR ${ }^{2}$}

In this study, the effects of cutting speed, feed rate and minimum quantity lubrication (MQL), frequently employed in machining applications, on main cutting force $(F c)$ and average surface roughness $(R a)$, resulting from turning AISI 4140, were investigated. For this purpose, analyses for Fc and Ra were performed utilizing Box-Behnken model. By using experimental parameters, the efficiency and the changes of the parameters on FC and Ra were examined with the help of 13 experiments. In addition, the effectiveness of design models was investigated by creating different design models. The high success rate modelling for Fc and Ra was realized with 99\% success as a result of analyses conducted according to Box-Behnken methods (BoxBehnken, Box-Behnken-Stepwise, Box-Behnken-Backward and BoxBehnken-Forward). The most effective parameter on $F c$ and Ra was found to be the feed rate according to analysis of variance (ANOVA). It was demonstrated that the estimations on the created Box-Behnken model were quite successful on the data initially entered into the system; and that $R 2$ values obtained for Fc and Ra were 0.999 and 0.996, respectively. It was determined that optimum parameters for Fc were feed rate $0.25 \mathrm{~mm} / \mathrm{rev}$, cutting speed $125 \mathrm{~m} / \mathrm{min}$ and cutting condition MQL2 $\mathrm{ml} / \mathrm{min}$, while they were feed rate $0.25 \mathrm{~mm} / \mathrm{rev}$, cutting speed $125 \mathrm{~m} / \mathrm{min}$ and cutting condition $M Q L 1 \mathrm{ml} / \mathrm{min}$ for $\mathrm{Ra}$.

Key words: Response surface methodology, Box-behnken design, Surface roughness, Main cutting forces, Machining parameters

\section{Introduction}

The most important parameters to be taken into consideration in machining are Fc and Ra which occur during machining operations. Since the primary aim in machining is to realize the highest amount of production with the lowest cost, this can be possible when values of $\mathrm{Fc}$ and $\mathrm{Ra}$ are minimized. Minimization of these values depends on optimizing cutting parameters and machining conditions. Today, optimization of cutting parameters in turning experiments utilized widely for most of the machining applications in industry is one of the primary issues which many researchers have

\footnotetext{
1 Department of Mechanical Engineering, University of Batman, Batman, Turkey, (huseyin.gurbuz@batman.edu.tr) https://orcid.org/0000-0003-1391-172X

2 Department of Mechanical Engineering, University of Siirt, Siirt, Turkey, (yunusemregonulacar@gmail.com) https://orcid.org/0000-0002-1565-8564
} 
focused on. Therefore, the use of Response Surface Method (RSM) has attracted the attention of numerous researchers for statistical analyses and optimization of Fc and Ra [1-14].

Aouici et al. analyzed Fc and Ra obtained by means of hard turning using CBN inserts with RSM. They developed mathematical models for Fc and Ra. In the light of results which they achieved, they found that while depth of cut and hardness of workpiece were effective on Fc, feed rate and hardness of workpiece were effective on Ra [1]. Hessainia et al. investigated Ra values occurring at the end of hard turning depending on tool vibration and cutting parameters by means of RSM. The authors stated that the most effective factor on Ra was feed rate; yet, tool vibrations did not have any effects on it. In addition, they established that predicted and experimental values were compatible with each other [2]. Aslan studied analysis of cutting parameters and optimization of Fc, tool wear and vibrations occurring in the machining of AISI 5140 by employing RSM. According to the ANOVA results, the author showed that the variables measured were reliable and appropriate for correlation. The author found that RSM provided optimization with high achievement rate (87.5\%). The author also determined that Fc, tool wear and vibration results were in relation with each other [3]. Sarıkaya and Güllü, under MQL conditions, investigated the effects of machining parameters on Ra in turning AISI 1050 by means of RSM and Taguchi design methods. They reported that the most effective parameter on Ra was feed rate; and they also established that MQL had a significant influence on it [4]. Kant and Sangwan utilized RSM in optimization of machining parameters to minimize Ra and energy consumption occurring as a result of turning AISI 1045 steel. They determined that in reducing energy consumption and $\mathrm{Ra}$, the most important parameters were primarily feed rate, depth of cut and cutting speed subsequently [5]. Subbaiah et al., by utilizing RSM, studied the Ra and tool wear occurring after hard turning of AISI 4340 steel with several hardness levels by means of wiper ceramic inserts. The authors established that feed rate and hardness of workpiece had an important effect on tool wear and $\mathrm{Ra}$ [6]. Teimouri et al. analyzed $\mathrm{Fc}$ and Ra which occurred after turning aluminum 7075 by using RSM. They determined that the optimum Fc and Ra values were feed rate $0.08 \mathrm{~m} / \mathrm{rev}$ and cutting speed $5.95 \mathrm{~m} / \mathrm{min}$ [7]. Bouacha et al. made statistical analyses of $\mathrm{Fc}$ and $\mathrm{Ra}$ in hard turning of AISI 52100 steel via CBN cutting tools using RSM. As a result of the study they conducted, they established that the cutting speed and feed rate had a leading effect on the Ra. They also revealed that the depth of cut is the most effective parameter on $\mathrm{Fc}$ [8]. Yadav investigated Ra occurring as a result of turning AISI 1040 steel with RSM. He found that the cutting speed is the most effective parameter on $\mathrm{Ra}$ values. He determined that the error rate between the experimental and estimated values was $6.1 \%$. He found that optimal conditions occurred when depth of cut, feed rate and cutting speed were $0.20 \mathrm{~mm}, 0.50 \mathrm{~mm} / \mathrm{rev}$ and $25 \mathrm{~m} / \mathrm{min}$, respectively [9]. Koyee et al. examined the cutting tool wear, Fc, chip volume ratio and cutting power in dry and wet turning of stainless steels with RSM. They estimated the experimental values with a 95\% success rate [10]. Tazehkandi et al. analysed the effect of machining parameters on $\mathrm{Fc}$ and Ra to eliminate the need for coolant in turning INCONEL 725 with coated cutting tools with RSM. They found that cutting tool coating had more significant effect than cutting coolant in reducing Fc and Ra values [11]. Lalwani et al. studied the effect of cutting parameters on $\mathrm{Fc}$ and Ra in MDN250 material finish turning with RSM. They found that cutting speed did not have an effect on Fc and Ra, and that the depth of cut and feed rate had a significant effect [12]. Asiltürk et al. determined that the optimization of the parameters had an influence on the Ra in turning Co28Cr6Mo medical material using RSM. They found that the optimum values to achieve minimum Ra were spindle rpm $318 \mathrm{rev} / \mathrm{min}$, depth of cut $0.7 \mathrm{~mm}$, feed rate $0.1 \mathrm{~mm} / \mathrm{rev}$ and cutting nose radius $0.8 \mathrm{~mm}$. In addition, the authors estimated the values of Ra with $92 \%$ success rate [13]. 
Chabbi et al. analyzed the effect of cutting parameters on Fc and Ra resulting from the machining of the polyoxymethylene polymer (POM C) material with RSM. They found that the most effective parameters on $\mathrm{Ra}$ were feed rate, then depth of cut, but cutting speed was not effective. Also, they established that feed rate and depth of cut had an important effect on Fc [14]. Çiçek et al. investigated the effect of cryogenic treatment and drilling parameters on hole and surface quality in drilling of AISI 304 steel using RSM and Taguchi method. According to the results of RSM and Taguchi, the authors found that feed rate and cutting speed were effective on surface roughness and roundness error [15].

As a result of the literature research, no study examining $\mathrm{Fc}$ and $\mathrm{Ra}$ values resulting from the machining of AISI 4140 steel at different MQL conditions and cutting parameters with the BoxBehnken method of RSM was found. The objective of this study is to reveal the effect of cutting and machining parameters on $\mathrm{Fc}$ and $\mathrm{Ra}$ after turning of the AISI 4140 steel using the Box-Behnken method, ANOVA analysis, optimization and the Stepwise, Backward and Forward models of BoxBehnken method.

\section{Material and Method}

\subsection{Workpiece material, inserts and tool holders}

In this study, the machining experiments were carried out after the preparation of samples of AISI 4140 steel material with $50 \mathrm{~mm}$ diameter and $300 \mathrm{~mm}$ length was made. The chemical compositions of the workpiece used are given in Table 1. Uncoated carbide cutting tools of Mitsubishi tool company in the form of SNMG 120408MS and with quality UTI20T/P30 were chosen as cutting inserts for machining experiments [16]. PSBNR 2525M12 tool holders suitable for the above mentioned tools were employed.

Table 1. Chemical compositions and hardness values of the workpiece material (AISI 4140)

\begin{tabular}{cccccc}
\hline \% C & \% Mn & \% P & \% Cr & \% S & \% Si \\
\hline $0.38-0.45$ & $0.60-0.90$ & $0.025(\max )$ & $0.90-1.20$ & $0.020-0.035$ & $0.40(\max )$ \\
$\% \mathbf{~ N i}$ & $\% \mathbf{S n}$ & $\% \mathbf{M o}$ & $\boldsymbol{\%} \mathbf{C u}$ & $\boldsymbol{\%} \mathbf{~ T i}$ & Hardness \\
$0.30(\max )$ & $0.050(\max )$ & $0.15-0.30$ & $0.30(\max )$ & $0.050(\max )$ & $34-45 \mathrm{HRC}$ \\
\hline
\end{tabular}

\subsection{Cutting parameters and experiments}

In machining experiments, Johnford TC $35 \mathrm{CNC}$ turning center was used for conducting the experiments. The suggestions of cutting tool manufacturer company and ISO 3685 standard were considered in establishing cutting parameters [16-17]. In Table 2, cutting parameters utilized in turning experiments are presented.

Table 2. Cutting parameters used in turning experiments

\begin{tabular}{cc}
\hline Depth of cut, $\mathbf{a}(\mathbf{m m})$ & 2.5 \\
\hline Feed rate, $\mathbf{f}(\mathbf{m m} / \mathbf{r e v})$ & $0.16-0.25-0.5$ \\
Cutting speed, $\mathbf{V}(\mathbf{m} / \mathbf{m i n})$ & $75-100-125-150$ \\
\hline
\end{tabular}

\subsection{Minimum quantity lubrication}

The lubricant was applied onto the cutting area in the experiments via two nozzles; and SKF brand UFB20-Basic Model was utilized as MQL unit. The pressure of system was 3 bars, the nozzle 
distance was $10 \mathrm{~mm}$ and the flow rate of lubricant was $0.35-0.8-1.7 \mathrm{ml} / \mathrm{min}$. Lubrioil brand lubricant suitable for machining steel workpieces was used for MQL application; and the properties of the lubricant is presented in Table 3.

Table 3. Lubrioil brand lubricant properties

\begin{tabular}{ccccc}
\hline Ignition temperature & Viscosity $\left(40^{\circ} \mathrm{C}\right)$ & Density $\left(20^{\circ} \mathrm{C}\right)$ & Color & Yield Point \\
\hline $265^{\circ} \mathrm{C}$ & $47 \mathrm{~mm}^{2} / \mathrm{s}$ & $0.92 \mathrm{~g} / \mathrm{cm}^{3}$ & Yellow & $-27^{\circ} \mathrm{C}$ \\
\hline
\end{tabular}

\subsection{Measurement of Fc and Ra}

Quartz crystal based KISTLER 9257B type dynamometer with Kistler 5070A Brand Multichannel Charge amplifier was employed in measuring Fc occurring during cutting experiments. Surface roughness ( $\mathrm{Ra}$ ) values, obtained from turning experiment, were measured with the Mahr Perthometer-M1 measuring device. In measuring Ra, measurements from three different points with distance of $5.6 \mathrm{~mm}$ of surfaces of all machined workpieces were taken and then the arithmetical mean was calculated.

\subsection{Response surface method (RSM)}

An experimental design method is used for modelling experimental system with fewer experiments. RSM can be modelled with four basic methods. They are Central Composite Face Centred (CCF), Central Composite Circumscribed (CCC), Central Composite Inscribed (CCI) and Box-Behnken models. The data in the corner points of RSM are entered as experimental parameters. The other points that can be created are determined according to alpha values. When input parameters in RSM design are determined, alpha parameters are used for each variable. In CCC and CCI models, the alpha value is determined as 1.682. However, it is possible to take alpha value as 1 as well. In this case, CCF and Box-Behnken design models are created [18-21]. In the studies carried out with RSM, Box-Behnken design model is frequently used [22-25]. This model is used in three level modelling, and it provides convenience to users due to its alpha value (1). In this study, Box-Behnken model is employed owing to the conveniences it provides. The designs made with the help of Box-Behnken design method take their origin from mathematical expressions. The mathematical equations that can be used with this method are given in Equation 1 - 4 [18-21].

Linear Equation $=\beta_{0}+\beta_{1} x l+\beta_{2} x v+\beta_{3} x f$

Linear and Quadratic $=\beta_{0}+\beta_{1} x l+\beta_{2} x v+\beta_{3} x f+\beta_{4} x l^{2}+\beta_{5} x v^{2}+\beta_{6} x f^{2}$

Linear and Interactive $=\beta_{0}+\beta_{1} x l+\beta_{2} x v+\beta_{3} x f+\beta_{4} x l x v+\beta_{5} x l x f+\beta_{6} x v x f$

Full Quadratic $=\beta_{0}+\beta_{1} x l+\beta_{2} x v+\beta_{3} x f+\beta_{4} x l^{2}+\beta_{5} x v^{2}+\beta_{6} x f^{2}+\beta_{7} x l x v+\beta_{8} x l x f+\beta_{9} x v x f$

In symbols taking place in equation $1-4 ; \beta_{0}, \beta_{1}, \beta_{n}, l, v, f$ represent basic coefficient, first term coefficient, $\mathrm{n}^{\text {th }}$ term coefficient, cutting conditions, cutting speed and feed rate, respectively. The parameters and their levels used in machining experiments are presented in Table 4.

Table 4. The parameters and their levels used in experiments

\begin{tabular}{ccccccc}
\hline Parameters & Symbol & Unit & Level -1 & Level 0 & Level 1 & Forecast analysis \\
\hline Cutting Conditions & $l$ & $(\mathrm{ml} / \mathrm{min})$ & MQL 1 & MQL 2 & MQL 3 & \\
\hline Feed Rate & $f$ & $(\mathrm{~mm} / \mathrm{rev})$ & 0.16 & 0.25 & 0.5 & 150 \\
\hline Cutting Speed & $v$ & $(\mathrm{~m} / \mathrm{min})$ & 75 & 100 & 125 & 150 \\
\hline
\end{tabular}


The thirteen data employed in Box-Behnken design method were chosen from the experimental set up and then used. The data used in experimental system are demonstrated in Table 5. As is seen in Table 5, the data of experiment number 7 , which has an average value of these experiments, were used in triplicate. Thus, a total of 13 experiments and 15 data were entered into the system. A three-stage structure was used in Box-Behnken design. In addition, the prediction ability of the created design for new data was investigated. Therefore, a total of 9 experimental data made with $150 \mathrm{~mm} / \mathrm{min}$ cutting speed was not employed in the design for measuring the estimation ability.

Table 5. Experimental data and used data

\begin{tabular}{|c|c|c|c|c|c|}
\hline $\begin{array}{l}\text { Experiment } \\
\text { Number }\end{array}$ & $\begin{array}{c}\text { Cutting } \\
\text { Conditions } \\
l(\mathrm{ml} / \mathrm{min}) \\
\end{array}$ & $\begin{array}{l}\text { Cutting Speed } \\
v(\mathrm{~m} / \mathrm{min})\end{array}$ & $\begin{array}{c}\text { Feed Rate } \\
f(\mathrm{~mm} / \mathrm{rev})\end{array}$ & $\begin{array}{l}\text { Main Cutting Forces } \\
\qquad F c(\mathbf{N})\end{array}$ & $\begin{array}{c}\text { Surface Roughness } \\
\qquad a(\mu \mathrm{m})\end{array}$ \\
\hline 1 & MQL 1 & 75 & 0.25 & 1403.96 & 2.908 \\
\hline 2 & MQL 1 & 100 & 0.16 & 984.69 & 1.080 \\
\hline 3 & MQL 1 & 100 & 0.50 & 2596.57 & 8.720 \\
\hline 4 & MQL 1 & 125 & 0.25 & 1352.92 & 2.361 \\
\hline 5 & MQL 2 & 75 & 0.16 & 1004.45 & 1.366 \\
\hline 6 & MQL 2 & 75 & 0.50 & 2617.52 & 9.080 \\
\hline 7 & MQL 2 & 100 & 0.25 & 1355.89 & 2.643 \\
\hline 8 & MQL 2 & 100 & 0.25 & 1355.89 & 2.643 \\
\hline 9 & MQL 2 & 100 & 0.25 & 1355.89 & 2.643 \\
\hline 10 & MQL 2 & 125 & 0.16 & 947.61 & 1.266 \\
\hline 11 & MQL 2 & 125 & 0.50 & 2520.77 & 9.246 \\
\hline 12 & MQL 3 & 75 & 0.25 & 1401.91 & 2.633 \\
\hline 13 & MQL 3 & 100 & 0.16 & 970.73 & 1.081 \\
\hline 14 & MQL 3 & 100 & 0.50 & 2552.87 & 8.938 \\
\hline 15 & MQL 3 & 125 & 0.25 & 1347.80 & 2.537 \\
\hline
\end{tabular}

\section{The Analysis of results}

\subsection{Analysis of values of $\mathrm{Fc}$}

ANOVA analysis was conducted to determine the effect of different cutting and machining conditions on the Fc. The aim of ANOVA is to analyze the effect of each parameter on the results obtained. The P value in an ANOVA table indicates the statistical significance of control factors. In general, the $\mathrm{p}$ value less than 0.05 indicates that it is statistically significant [26-28]. ANOVA analysis of Box-Behnken model for $\mathrm{Fc}$ is given in Table 6. Considering the $\mathrm{p}$ values in Table 6, it is seen that it has had an effect of the cutting speed $(0.000<0.005)$, feed rate $(0.000<0.005)$ and feed rate*feed rate $(0.000<0.005)$ on Fc. According to ANOVA analysis, it was determined that the feed rate $(99.75 \%)$ was the most effective parameter on Fc. This situation is in line with the studies in the literature [12, 14]. In the literature, the results obtained by many researchers have emphasized that the most effective parameter on $\mathrm{Fc}$ is feed rate. As a result, in this study, it was determined that feed rate is more effective on Fc than cutting speed and cutting conditions. The Box-Behnken model aims to achieve the most appropriate result by using all parameters in the given experimental set. However, it is also possible to use different types of elimination to achieve optimal results. In these elimination processes, the p-value used in the effectiveness analysis of the model is entered as the elimination coefficient. It is seen that some $\mathrm{p}$ values of the parameters seen in Table 6 are greater than 0.05 , and have no significant relationship with the problem. In particular, the $\mathrm{p}$ value of the cutting condition (l)*cutting speed (v) parameter is far from to be meaningful. Therefore, three different elimination methods are used to increase the stability of the test results. These methods are Stepwise, which has both forward 
and backward elimination, Backward, which has only backward elimination, and Forward, which has only forward elimination. Firstly, $\alpha$ coefficient values were entered into the program as $\alpha=0.15, \alpha=$ 0.1 and $\alpha=0.25$ for the Stepwise, Backward and Forward models, which are the general elimination values in the elimination processes, respectively. At the same time, formulas with the desired $\alpha=0.05$ coefficient were obtained in all 3 models.

Table 6. ANOVA analysis created for Fc

\begin{tabular}{lcccccc}
\hline \multicolumn{1}{c}{ Parameters } & DF $^{1}$ & Adj SS $^{2}$ & Adj MS $^{3}$ & F $^{4}$-Value & P5- Value $^{5}$ & $\begin{array}{c}\text { PCR }^{\mathbf{6}} \\
\text { Contribution }\end{array}$ \\
\hline Model & 9 & 5716451 & 635161 & 12382.93 & 0.000 & $100.00 \%$ \\
\hline Lineer & 3 & 5098164 & 1699388 & 33130.81 & 0.000 & $99.91 \%$ \\
\hline Cutting conditions & 1 & 773 & 773 & 15.07 & 0.012 & $0.01 \%$ \\
\hline Cutting speed & 1 & 8942 & 8942 & 174.33 & 0.000 & $0.15 \%$ \\
\hline Feed rate & 1 & 5088449 & 5088449 & 99203.02 & 0.000 & $99.75 \%$ \\
\hline Square & 3 & 4089 & 1363 & 26.57 & 0.002 & $0.07 \%$ \\
\hline Cutting conditions *Cutting conditions & 1 & 549 & 549 & 10.70 & 0.022 & $0.01 \%$ \\
\hline Cutting speed*Cutting speed & 1 & 271 & 271 & 5.28 & 0.070 & $0.00 \%$ \\
\hline Feed rate * Feed rate & 1 & 3609 & 3609 & 70.36 & 0.000 & $0.06 \%$ \\
\hline 2- way Interaction & 3 & 985 & 328 & 6.40 & 0.036 & $0.02 \%$ \\
\hline Cutting conditions *Cutting speed & 1 & 2 & 2 & 0.05 & 0.839 & $0.00 \%$ \\
\hline Cutting conditions*Feed rate & 1 & 390 & 390 & 7.60 & 0.040 & $0.01 \%$ \\
\hline Cutting speed* Feed rate & 1 & 593 & 593 & 11.55 & 0.019 & $0.01 \%$ \\
\hline Error & 5 & 256 & 51 & & & $0.00 \%$ \\
\hline Lack-of-Fit & 3 & 256 & 85 & $*$ & $*$ & $0.00 \%$ \\
\hline Pure error & 2 & 0 & 0 & & & $0.00 \%$ \\
\hline Total & 14 & 5716708 & & & & $100.00 \%$ \\
\hline An ANOVA
\end{tabular}

An ANOVA table gives these: degrees of freedom $(\mathrm{DF})^{1}$, sum of squares $(\mathrm{SS})^{2}$, mean of squares $(\mathrm{MS})^{3}$, statistics $(\mathrm{F})^{4}$ values, $(\mathrm{P})^{5}$ values indicating the significance level of each variable on the results and percentage contribution rates $(\mathrm{PCR})^{6}$.

In case these elimination coefficients are reduced towards the desired value of $p$, the equation parameters decrease. The $\mathrm{R}^{2}$ values obtained by other three design approaches that eliminate the model and the formulas created by the models for Fc values are shown in Table 7. As can be seen in Table 7, $\mathrm{R}^{2}$ value obtained with Box-Behnken method is quite high; and also, the corrected $\mathrm{R}^{2}$ value was found to be minimum $99.94 \%$. It is understood that the parameter " $0.00311 \mathrm{xv"} \mathrm{created} \mathrm{in} \mathrm{the} \mathrm{first} \mathrm{model,}$ which has a very limited effect on the experimental results in all three elimination models using the standard elimination values $(\alpha)$, is removed from the formula.

Table 7. Modellings carried out for Fc values and their results

\begin{tabular}{|c|c|c|c|}
\hline Model & $\mathbf{R}^{2}$ & $\mathbf{R}^{2}(\mathbf{a d j})$ & $\begin{array}{c}\text { Formula } \\
\end{array}$ \\
\hline Box-Behnken & $\% 100$ & $\% 99.99$ & $\begin{array}{l}547.1-37.8 l-3.19 v+4110 f+12.19 l^{2}+0.0137 v^{2}+1459 f^{2}-0.031 l x v-55.1 l x f- \\
2.717 v x f\end{array}$ \\
\hline $\begin{array}{l}\text { Box-Behnken } \\
\text { Stepwise }(\alpha=0.15)\end{array}$ & $\% 100$ & $\% 99.99$ & $553.2-40.9 l-3.25 v+4110 f+12.19 l^{2}+0.01370 v^{2}+1459 f^{2}-55.1 l x f-2.717 v x f$ \\
\hline $\begin{array}{l}\text { Box-Behnken } \\
\text { Stepwise }(\alpha=0.05)\end{array}$ & $\% 99.96$ & $\% 99.94$ & $467.1-1.294 v+3772 f+1393 f^{2}$ \\
\hline $\begin{array}{l}\text { Box-Behnken } \\
\text { Backward }(\alpha=0.1)\end{array}$ & $\% 100$ & $\% 99.99$ & $553.2-40.9 l-3.25 v+4110 f+12.19 l^{2}+0.01370 v^{2}+1459 f^{2}-55.11 x f-2.717 v x f$ \\
\hline $\begin{array}{l}\text { Box-Behnken } \\
\text { Backward }(\alpha=0.05)\end{array}$ & $\% 100$ & $\% 99.99$ & $553.2-40.9 l-3.25 v+4110 f+12.19 l^{2}+0.01370 v^{2}+1459 f^{2}+55.1 l x f-2.717 v x f$ \\
\hline $\begin{array}{l}\text { Box-Behnken } \\
\text { Forward }(\alpha=0.25) \\
\end{array}$ & $\% 100$ & $\% 99.99$ & $553.2-40.9 l-3.25 v+4110 f+12.19 l^{2}+0.01370 v^{2}+1459 f^{2}-55.1 l x f-2.717 v x f$ \\
\hline $\begin{array}{l}\text { Box-Behnken } \\
\text { Forward }(\alpha=0.05)\end{array}$ & $\% 99.96$ & $\% 99.94$ & $467.1-1.294 v+3772 f+1393 f^{2}$ \\
\hline
\end{tabular}


This expression, which has almost no effect on the experimental results, was eliminated, thus a better model structure was obtained. In the elimination models using the elimination value $\alpha=0.05$, high $\mathrm{R}^{2}$ values were obtained with four parameters when using Stepwise and Forward functions. When both ANOVA analysis and models are examined, it is determined that the effectiveness of some parameters affecting the result is lower than other parameters. The main effect plot showing the effect of machining parameters and cutting conditions on $\mathrm{Fc}$ is given in Figure 2. As seen in Figure 2, the change in all three parameters causes the change of Fc. However, when the parameters affecting $\mathrm{Fc}$ are examined (Figure 2), it is seen that the cutting condition and cutting speed parameters have very limited effect. The change of the feed rate parameter creates a linear-line curve; and the increasing feed rate directly increases Fc.

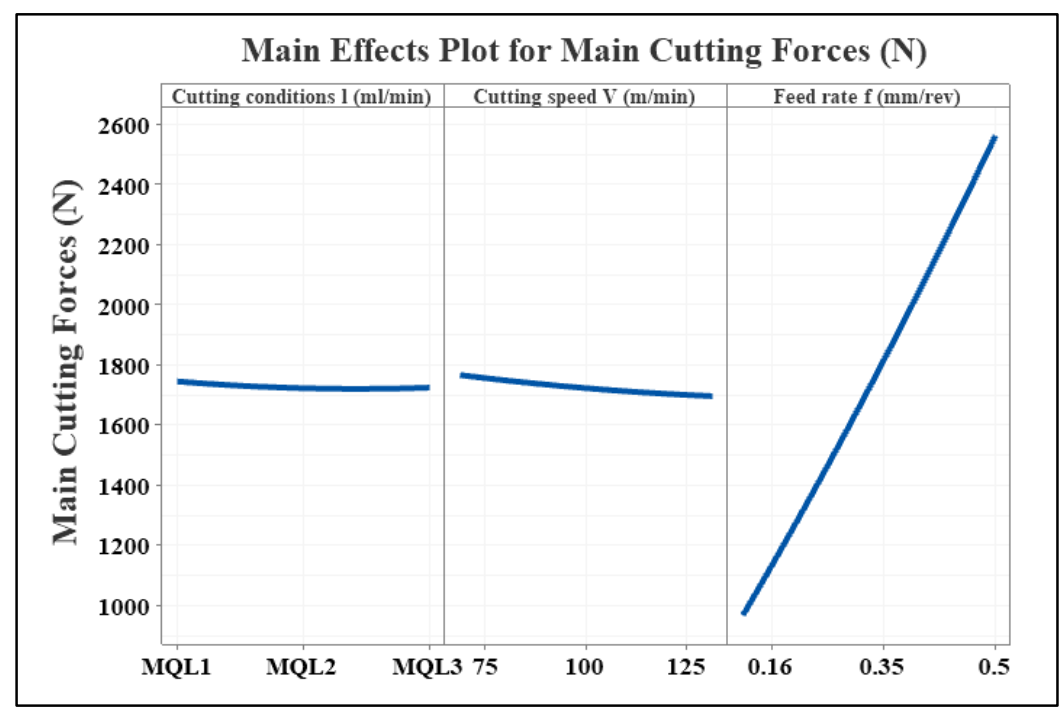

Figure 2. Effect of parameters on Fc

Each optimization is conducted depending on certain criteria. The criterion determined for the optimization in this study obtains the lowest Fc. Because it is necessary to minimize Fc values in order to reduce machining cost of workpiece. Minimization of Fc depends on optimization of cutting parameters. Values and graphs showing the intervals at which the machining parameters and cutting conditions should be used are given in Table 8 and Figure 3. These values and graphs show the lowest target $\mathrm{Fc}$ targeted in the experiments. The lowest optimized Fc is $\mathrm{Fc}=947.61 \mathrm{~N}$.

Table 8. Response optimization for Fc (N)

\begin{tabular}{cccccccccc}
\hline & & \multicolumn{3}{c}{ Optimal conditions } & & & & & \\
\cline { 3 - 6 } Parameter & Goal & $\begin{array}{c}\text { Cutting } \\
\text { conditions } \\
(\mathbf{m l} / \mathbf{m i n})\end{array}$ & $\begin{array}{c}\text { Cutting } \\
\text { speed } \\
(\mathbf{m} / \mathbf{m i n})\end{array}$ & $\begin{array}{c}\text { Feed rate } \\
(\mathbf{m m} / \mathbf{r e v})\end{array}$ & Lower & Target & $\begin{array}{c}\text { Predicted } \\
\text { response }\end{array}$ & Upper & Desirability \\
\hline Fc (N) & Minimum & MQL 2 & 125 & 0.16 & 947.61 & 947.61 & 951.54 & 2617.52 & 1 \\
\hline
\end{tabular}

When the graphs in Figure 3 and the values in Table 8 are examined, it is necessary to select the feed rate as $0.16 \mathrm{~mm} / \mathrm{rev}$, the cutting speed as $125 \mathrm{~m} / \mathrm{min}$ and the cutting condition as MQL2 for the optimal conditions of the lowest Fc that can occur under the current experimental conditions. 


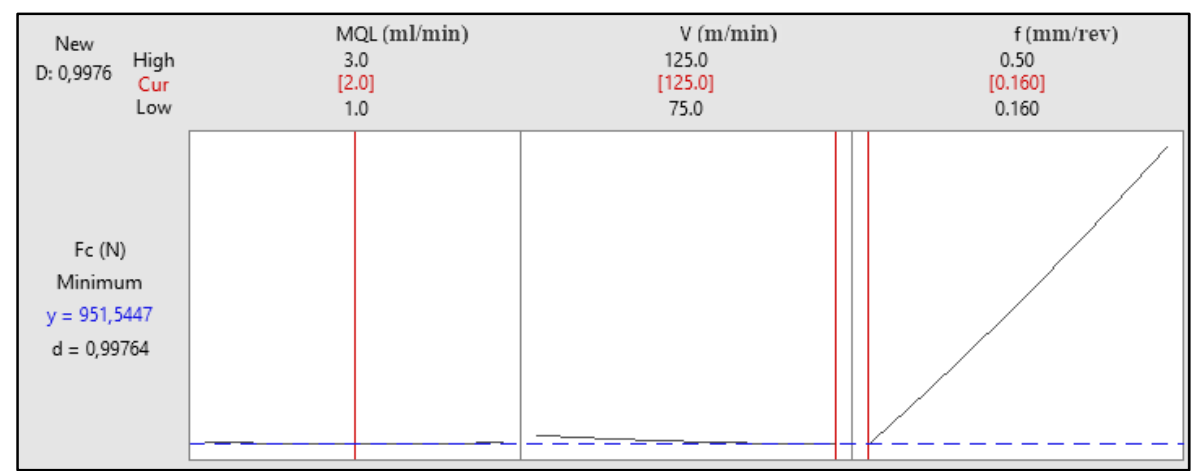

Figure 3. Optimization results for Fc at optimal conditions according to RSM

\subsection{Analysis of Ra values}

ANOVA analysis, which was created to observe the effect of machining and cutting parameters on $\mathrm{Ra}$, is presented in Table 9. In Table 9, it is understood that feed rate and feed rate*feed rate interaction have an effect on Ra when $\mathrm{p}$ values of machining parameters are examined. According to ANOVA results, it is established that the most effective parameter on $\mathrm{Ra}$ is feed rate $(98.79 \%)$. This is in line with the studies in the literature [4-9, 8, 26]. In the literature, it was stated that the feed rate is the most effective parameter when looking at the studies analyzing the effect of machining parameters on Ra.

Table 9. ANOVA analysis created for Ra values

\begin{tabular}{lcccccc}
\hline \multicolumn{1}{c}{ Parameters } & DF & Adj SS & Adj MS & F-Value & P-Value & $\begin{array}{c}\text { PCR } \\
\text { Contribution }\end{array}$ \\
\hline Model & 9 & 144.762 & 16.085 & 1661.74 & 0.000 & $99.97 \%$ \\
\hline Lineer & 3 & 121.634 & 40.545 & 4188.76 & 0.000 & $98.82 \%$ \\
\hline Cutting conditions & 1 & 0.007 & 0.007 & 0.70 & 0.441 & $0.00 \%$ \\
\hline Cutting speed & 1 & 0.018 & 0.018 & 1.81 & 0.236 & $0.03 \%$ \\
\hline Feed rate & 1 & 121.610 & 121.610 & 12563.76 & 0.000 & $98.79 \%$ \\
\hline Square & 3 & 1.543 & 0.514 & 53.12 & 0.000 & $1.07 \%$ \\
\hline Cutting conditions * Cutting conditions & 1 & 0.094 & 0.094 & 9.67 & 0.027 & $0.11 \%$ \\
\hline Cutting speed*Cutting speed & 1 & 0.058 & 0.058 & 6.01 & 0.058 & $0.02 \%$ \\
\hline Feed rate x Feed rate & 1 & 1.354 & 1.354 & 139.93 & 0.000 & $0.94 \%$ \\
\hline 2- way Interaction & 3 & 0.112 & 0.037 & 3.86 & 0.090 & $0.08 \%$ \\
\hline Cutting conditions *Cutting speed & 1 & 0.051 & 0.051 & 5.25 & 0.071 & $0.04 \%$ \\
\hline Cutting conditions*Feed rate & 1 & 0.019 & 0.019 & 1.98 & 0.218 & $0.01 \%$ \\
\hline Cutting speed* Feed rate & 1 & 0.042 & 0.042 & 4.36 & 0.091 & $0.03 \%$ \\
\hline Error & 5 & 0.048 & 0.010 & & & $0.03 \%$ \\
\hline Lack-of-Fit & 3 & 0.048 & 0.016 & $*$ & $*$ & $0.03 \%$ \\
\hline Pure error & 2 & 0.000 & 0.000 & & & $0.00 \%$ \\
\hline Total & 14 & 144.810 & & & & $100.00 \%$ \\
\hline
\end{tabular}

ANOVA analysis, created for Ra values (Table 9) and for Fc values, show similarity. It is seen that some $\mathrm{p}$ values in Table 9 are high; and there is no meaningful relation with the problem. BoxBehnken method utilized for the analysis of the $\mathrm{Fc}$ is used in the analysis of Ra values. In addition to Box-Behnken model, six elimination methods were applied. $\mathrm{R}^{2}$ values obtained as a result of these processes and the formulas made by these models can be seen in Table 10. Elimination methods and elimination coefficients that were used for analysing Fc were employed to increase the stability of experimental results. The models and $\mathrm{R}^{2}$ values obtained by this way can be seen in Table 10 . As is 
seen in Table 10, high $\mathrm{R}^{2}$ values are attained with all Box-Behnken models. When elimination methods are used, it is seen that $\mathrm{p}$ values are higher than that of 0.05 , and thus they are eliminated. When the results obtained with different elimination methods for Ra are examined, it is observed that the same model is formed in five different elimination methods. It is revealed that quite high $\mathrm{R}^{2}$ values can be obtained related only with efficiency of feed rate parameter.

Table 10. Modellings conducted for Ra and their results

\begin{tabular}{|c|c|c|c|}
\hline Model & $\mathbf{R}^{2}$ & $\mathbf{R}^{2}(\mathbf{a d j})$ & Formula \\
\hline Box-Behnken & $\% 99.97$ & $\% 99.91$ & $\begin{array}{l}3.23+0.089 l-0.0587 v+1.21 f-0.1592 l^{2}+0.000201 v^{2}+28.26 f^{2}+0.00451 l x v+ \\
0.387 l x f+0.0229 v x f\end{array}$ \\
\hline $\begin{array}{l}\text { Box-Behnken } \\
\text { Stepwise }(\alpha=0.15)\end{array}$ & $\% 99.75$ & $\% 99.70$ & $-0.202+4.21 f+28.37 f^{2}$ \\
\hline $\begin{array}{l}\text { Box-Behnken } \\
\text { Stepwise }(\alpha=0.05)\end{array}$ & $\% 99.75$ & $\% 99.70$ & $-0.202+4.21 f+28.37 f^{2}$ \\
\hline $\begin{array}{l}\text { Box-Behnken } \\
\text { Backward }(\alpha=0.1)\end{array}$ & $\% 99.82$ & $\% 99.75$ & $-0.866+0.691 l+4.57 f-0.1689 l^{2}+27.83 f^{2}$ \\
\hline $\begin{array}{l}\text { Box-Behnken } \\
\text { Backward }(\alpha=0.05)\end{array}$ & $\% 99.75$ & $\% 99.70$ & $-0.202+4.21 f+28.37 f^{2}$ \\
\hline $\begin{array}{l}\text { Box-Behnken } \\
\text { Forward }(\alpha=0.25) \\
\end{array}$ & $\% 99.75$ & $\% 99.70$ & $-0.202+4.21 f+28.37 f^{2}$ \\
\hline $\begin{array}{l}\text { Box-Behnken } \\
\text { Forward }(\alpha=0.05)\end{array}$ & $\% 99.75$ & $\% 99.70$ & $-0.202+4.21 f+28.37 f^{2}$ \\
\hline
\end{tabular}

The main effect plot of cutting and machining conditions on $\mathrm{Ra}$ is given in Figure 4. When the graphs in Figure 4 are studied, it can be observed that all parameters are effective on Ra. However, it is understood from Figure 4 that the effect of feed rate on Ra is higher than the effect of MQL and cutting speed. In other words, that feed rate has more effect on Ra can be explained with the fact that the angle of the main effect curve created on graphic is bigger than the two parameters.

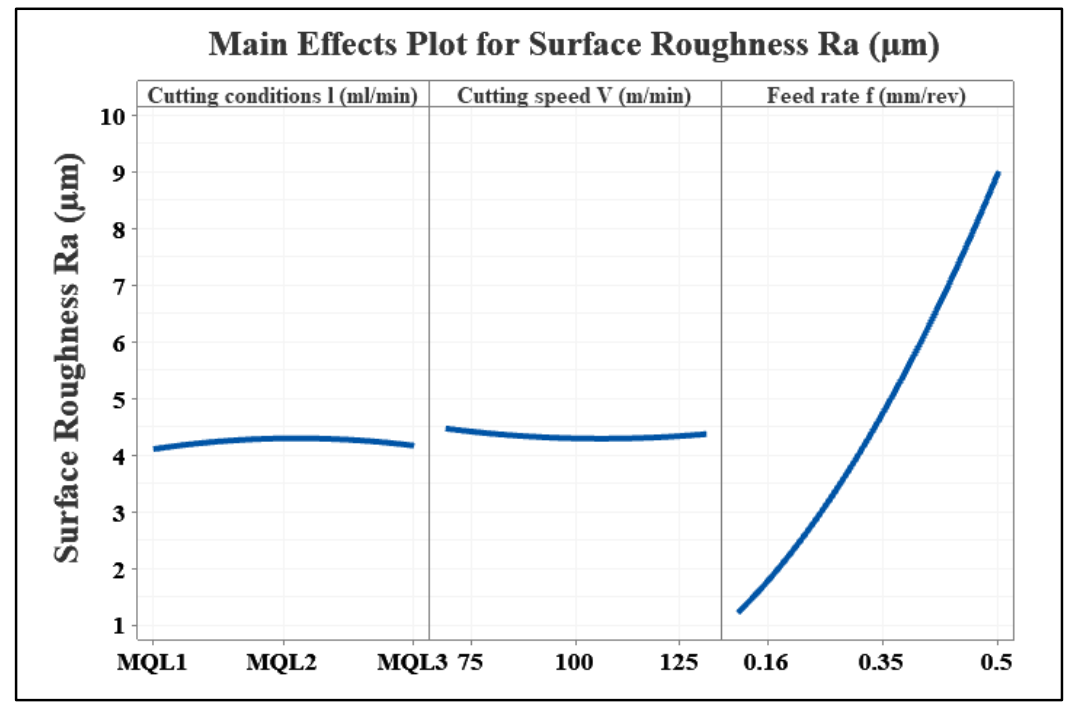

Figure 4. Effect of parameters on Ra

Low $\mathrm{Ra}$ values come first in the requirements of workpieces desired to be produced by chip removal method. The aim of machining operation is not only giving shape to the workpieces but also manufacturing an ideal surface quality with a certain tolerance and accuracy in terms of geometry and dimension. Because of these reasons, the criterion determined in this study for optimization of Ra is to obtain the lowest Ra value. In this study, values and graphs showing the values of machining 
parameters and cutting conditions are given in Table 11 and Figure 5 to obtain the lowest Ra, which is of great importance in manufacturing.

Table 11. Response optimization for $\operatorname{Ra}(\mu \mathrm{m})$

\begin{tabular}{|c|c|c|c|c|c|c|c|c|}
\hline \multirow[b]{2}{*}{ Parameter } & \multirow[b]{2}{*}{ Goal } & \multicolumn{3}{|c|}{ Optimal conditions } & \multirow[b]{2}{*}{ Lower } & \multirow[b]{2}{*}{ Target } & \multirow[b]{2}{*}{$\begin{array}{c}\text { Predicted } \\
\text { response }\end{array}$} & \multirow[b]{2}{*}{ Upper Desirability } \\
\hline & & $\begin{array}{l}\text { Cutting } \\
\text { conditions } \\
(\mathrm{ml} / \mathrm{min})\end{array}$ & $\begin{array}{l}\text { Cutting } \\
\text { speed } \\
(\mathrm{m} / \mathrm{min})\end{array}$ & $\begin{array}{l}\text { Feed rate } \\
(\mathrm{mm} / \mathrm{rev})\end{array}$ & & & & \\
\hline $\mathrm{Ra}(\mu \mathrm{m})$ & Minimum & MQL 1 & 125 & 0.16 & 1.08 & 1.08 & 0.95 & 9.24 \\
\hline
\end{tabular}

The value chosen for optimization is $\mathrm{Ra}=1.080 \mu \mathrm{m}$ for the lowest $\mathrm{Ra}$. When Figure 5 and Table 11 are examined in terms of optimal conditions of the lowest $\mathrm{Ra}$, which can be attained under experimental conditions, it is clearly seen that it is necessary to choose the feed rate as $0.16 \mathrm{~mm} / \mathrm{rev}$, cutting speed as $125 \mathrm{~m} / \mathrm{min}$ and cutting condition as MQL1.

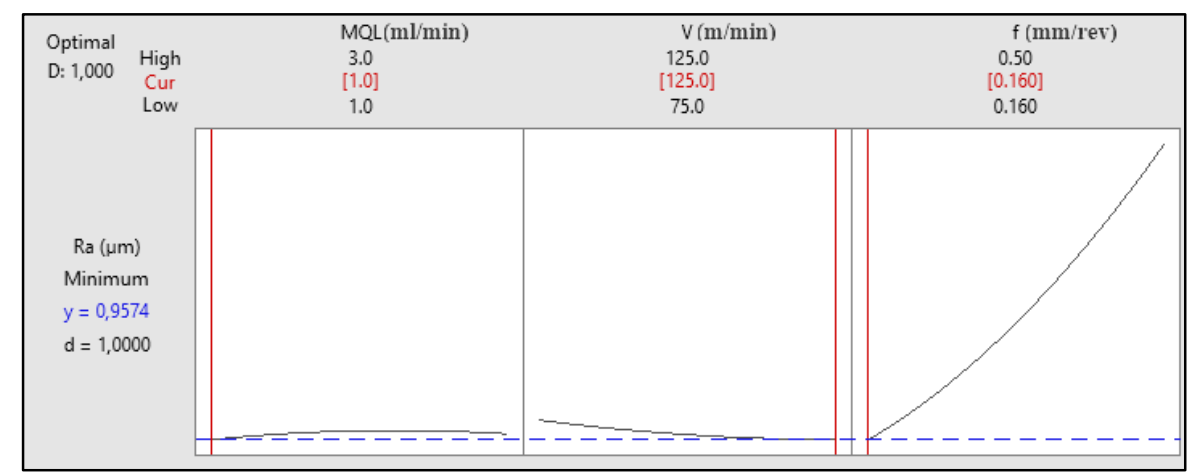

Figure 5. Optimization results for Ra at optimal conditions according to RSM

\subsection{The estimation ability of models created}

Measuring the estimation ability of models created by Box-Behnken experiment design method using different data determines the stability of this design method. Thus, some experimental data not included in the experimental set are intended to generate estimates with the model created. The cutting speed parameter in the experimental set has four different values. However, of these values, 150 $\mathrm{m} / \mathrm{min}$ is excluded while 75,100 and $125 \mathrm{~m} / \mathrm{min}$ are included in the experimental design method. The reason for this is that cutting speed is selected as $150 \mathrm{~m} / \mathrm{min}$ and analysed instead of an intermediate value of parameters included in the experimental set in measuring the estimation ability. The experimental results and estimated results by experimental design method can be seen in Figure 6.

When the experimental results are compared to estimated results, a great similarity is observed between the data of both Fc and Ra. The similarity of estimated results and experimental results are shown with $\mathrm{R}^{2}$ values so that the estimation ability of models can be understood better. The estimation results of Fc and Ra obtained by using Box-Behnken method of RSM, and the regression value of experimental values $\left(\mathrm{R}^{2}\right)$ are found as 0.999 and 0.996 , respectively. The estimation ability of the models shows how successful it is in estimating Fc and Ra. As a result, the created model produces highly successful results for data which are not previously entered to the model. 


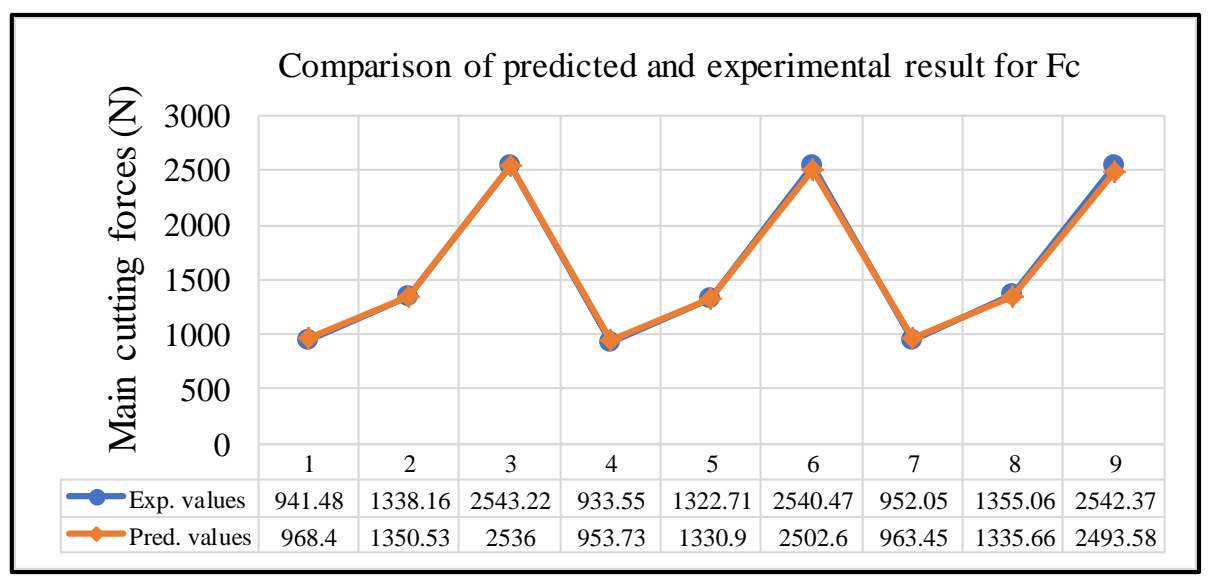

(a)

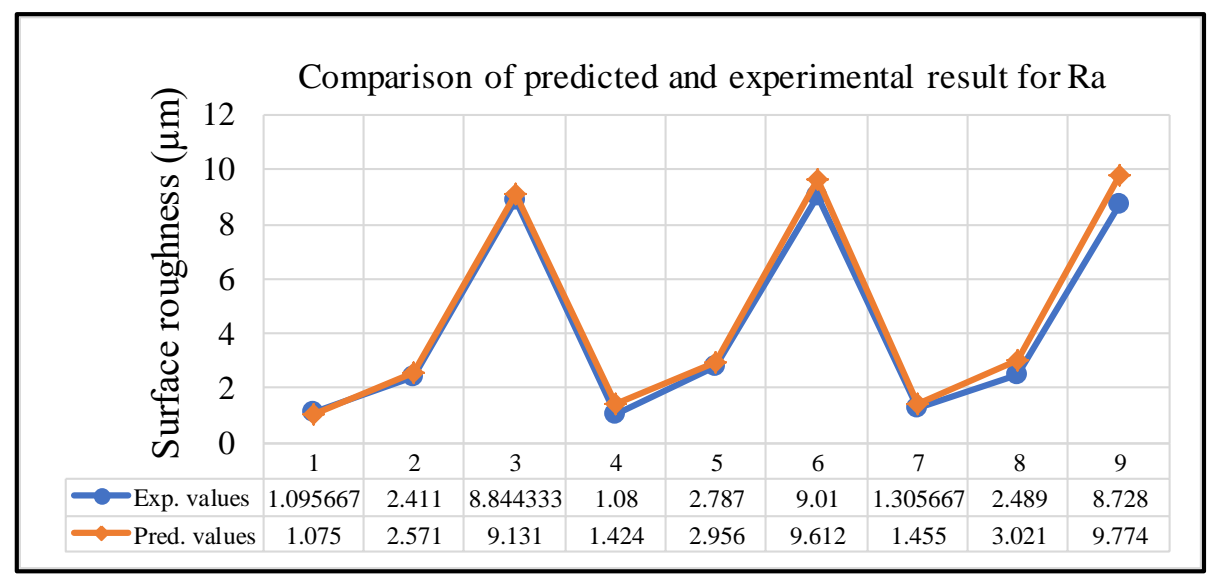

(b)

Figure 6. Comparison of experimental and estimated results for Fc and Ra

\section{Results}

The following results are obtained at the end of this study in which the effectiveness of cutting condition, feed rate and cutting speed parameters affecting values of $\mathrm{Fc}$ and Ra is investigated with the help of Box-Behnken method of RSM:

- Over 99\% successful results were obtained with Box-Behnken method and Stepwise, Backward and Forward models of Box-Behnken method applied to Fc and Ra.

- It was seen that the main factor affecting both $\mathrm{Fc}$ and $\mathrm{Ra}$ was feed rate according to ANOVA analyses.

- It was established that the optimum parameters necessary for the most ideal Ra value were feed rate $0.16 \mathrm{~mm} / \mathrm{rev}$, cutting speed $125 \mathrm{~m} / \mathrm{min}$ and cutting condition MQL1.

- It was found that $\mathrm{R}^{2}$ value of estimations of $\mathrm{Fc}$ was 0.999 and $\mathrm{Ra}$ was 0.996 when the estimation ability of the Box-Behnken model was investigated with data which were not entered into the Box-Behnken model previously. The obtained $\mathrm{R}^{2}$ values showed how successful Box-Behnken model was in predicting. 
- It can be stated that the method applied in this study can be reliably used for similar studies by looking at the consistency of the results of ANOVA, Box-Behnken models and prediction graphics.

- For the most ideal Fc, the optimum parameters were obtained when feed rate was 0.16 $\mathrm{mm} / \mathrm{rev}$, cutting speed was $125 \mathrm{~m} / \mathrm{min}$ and cutting condition was MQL2.

\section{Acknowledgement}

This research was given support by the Batman University Scientific Research Projects Unit (BTUBAP). project no 2017-GRADUATE-2. Thanks BTUBAP for financial support.

\section{References}

[1] Aouici, H., Yallese, M. A., Chaoui, K., Mabrouki, T., Rigal, J. F. (2012). Analysis of surface roughness and cutting force components in hard turning with CBN tool: Prediction model and cutting conditions optimization. Measurement, 45(3), 344-353.

[2] Hessainia, Z., Belbah, A., Yallese, M. A., Mabrouki, T., Rigal, J. F. (2013). On the prediction of surface roughness in the hard turning based on cutting parameters and tool vibrations. Measurement, 46(5), 1671-1681.

[3] Aslan, A. (2020). Optimization and Analysis of Process Parameters for Flank Wear, Cutting Forces and Vibration in Turning of AISI 5140: A Comprehensive Study. Measurement, 107959.

[4] Sarıkaya, M., Güllü, A. (2014). Taguchi design and response surface methodology based analysis of machining parameters in CNC turning under MQL. Journal of Cleaner Production, 65, 604616.

[5] Kant, G., Sangwan, K. S. (2014). Prediction and optimization of machining parameters for minimizing power consumption and surface roughness in machining. Journal of cleaner production, 83, 151-164.

[6] Subbaiah, K. V., Raju, C., Suresh, C. (2020). Parametric analysis and optimization of hard turning at different levels of hardness using wiper ceramic insert. Measurement, 158, 107712.

[7] Teimouri, R., Amini, S., Mohagheghian, N. (2017). Experimental study and empirical analysis on effect of ultrasonic vibration during rotary turning of aluminum 7075 aerospace alloy. Journal of Manufacturing Processes, 26, 1-12.

[8] Bouacha, K., Yallese, M. A., Mabrouki, T., Rigal, J. F. (2010). Statistical analysis of surface roughness and cutting forces using response surface methodology in hard turning of AISI 52100 bearing steel with CBN tool. International Journal of Refractory Metals and Hard Materials, 28(3), 349-361.

[9] Yadav, R. N. (2017). A hybrid approach of Taguchi-Response surface methodology for modeling and optimization of duplex turning process. Measurement, 100, 131-138.

[10] Koyee, R. D., Heisel, U., Eisseler, R., Schmauder, S. (2014). Modeling and optimization of turning duplex stainless steels. Journal of Manufacturing Processes, 16(4), 451-467.

[11] Tazehkandi, A. H., Pilehvarian, F., Davoodi, B. (2014). Experimental investigation on removing cutting fluid from turning of Inconel 725 with coated carbide tools. Journal of Cleaner Production, 80, 271-281. 
[12] Lalwani, D. I., Mehta, N. K., Jain, P. K. (2008). Experimental investigations of cutting parameters influence on cutting forces and surface roughness in finish hard turning of MDN250 steel. Journal of materials processing technology, 206(1-3), 167-179.

[13] Asiltürk, I., Neşeli, S., Ince, M. A. (2016). Optimisation of parameters affecting surface roughness of $\mathrm{Co} 28 \mathrm{Cr} 6 \mathrm{Mo}$ medical material during $\mathrm{CNC}$ lathe machining by using the Taguchi and RSM methods. Measurement, 78, 120-128.

[14] Chabbi, A., Yallese, M. A., Meddour, I., Nouioua, M., Mabrouki, T., Girardin, F. (2017). Predictive modeling and multi-response optimization of technological parameters in turning of Polyoxymethylene polymer (POM C) using RSM and desirability function. Measurement, 95, 99115.

[15] Çiçek, A., Kıvak, T., Ekici, E. (2015). Optimization of drilling parameters using Taguchi technique and response surface methodology (RSM) in drilling of AISI 304 steel with cryogenically treated HSS drills. Journal of Intelligent Manufacturing, 26(2), 295-305.

[16] Mitsubishi Carbide, Guide to turning inserts. Japan, 2019.

[17] STN ISO 3685, Tool-Life Testing with Single-Point Turning Tools, Turkey, 1999.

[18] Rao R.V., Advanced Modeling and Optimization of Manufacturing Processes, Springer, London, 2011.

[19] Myres, R. H., Montgomery D. C. and Anderson-Cook C. M., Response Surface Methodology, Wiley, New York, 2009.

[20] Sönmez, F., Başak, H., Baday, Ş. (2016). Analysis of Burnishing Process with Response Surface Method. Gazi University Science Journal: PART:C 'Design and Technology', 4(4), 275-283.

[21] Montgomery, D. C., Design and Analysis of Experiments, Wiley, New York, 2004.

[22] Vinayagamoorthy, R. (2017). Parametric optimization studies on drilling of sandwich composites using the Box-Behnken design. Materials and Manufacturing Processes, 32(6), 645-653.

[23] Goud, V., Ramasamy, A., Das, A., Kalyanasundaram, D. (2019). Box-Behnken technique based multi-parametric optimization of electrostatic spray coating in the manufacturing of thermoplastic composites. Materials and Manufacturing Processes, 34(14), 1638-1645.

[24] Kandananond, K. (2010). Using the response surface method to optimize the turning process of AISI 12L14 steel. Advances in Mechanical Engineering, 2, 362406.

[25] Nouioua, M., Yallese, M.A., Khettabi, R., Belhadi, S., Bouhalais, M. L., Girardin, F. (2017). Investigation of the performance of the MQL, dry, and wet turning by response surface methodology (RSM) and artificial neural network (ANN). The International Journal of Advanced Manufacturing Technology, 93(5-8), 2485-2504.

[26] Camposeco-Negrete, C. (2013). Optimization of cutting parameters for minimizing energy consumption in turning of AISI 6061 T6 using Taguchi methodology and ANOVA. Journal of Cleaner Production, 53, 195-203.

[27] Das, A., Patel, S. K., Hotta, T. K., Biswal, B. B. (2019). Statistical analysis of different machining characteristics of EN-24 alloy steel during dry hard turning with multilayer coated cermet inserts. Measurement, 134, 123-141.

[28] Kivak, T. (2014). Optimization of surface roughness and flank wear using the Taguchi method in milling of Hadfield steel with PVD and CVD coated inserts. Measurement, 50, 19-28. 